\title{
Sex Differences in Association Between Body Composition and Frailty or Physical Performance in Community-Dwelling Older Adults
}

Yunsoo Soh ( $\sim$ soyuns@gmail.com )

Kyungpook National University Hospital https://orcid.org/0000-0001-8368-4900

Chang Won Won MD

Kyung Hee University College of Medicine: Kyung Hee University School of Medicine

\section{Research article}

Keywords: Aging, body composition, frailty, obesity, body mass index

Posted Date: September 24th, 2020

DOI: https://doi.org/10.21203/rs.3.rs-69908/v1

License: (c) (1) This work is licensed under a Creative Commons Attribution 4.0 International License.

Read Full License

Version of Record: A version of this preprint was published at Medicine on January 29th, 2021. See the published version at https://doi.org/10.1097/MD.0000000000024400. 


\section{Abstract}

\section{Background}

Frailty is a common geriatric condition due to aging, defined as a decrease in the functional reserve to maintain the homeostasis. As part of the aging process, body composition changes occur. This study investigated the relationship between body composition and frailty in a community-dwelling elderly Korean population.

\section{Methods}

This cross-sectional cohort study analyzed data of 2,385 elderly participants (aged 70-84 years, 1131 males and 1254 females) of the Korean Frailty and Aging Cohort Study from 2016 to 2017. Body composition, including total and trunk fat masses and fat-free mass, were measured with dual-energy Xray absorptiometry. Fat mass index (FMI), trunk fat mass index (TFMI), and fat-free mass index (FFMI) represented total fat mass, trunk fat mass, and fat-free mass according to height. Based on the frailty index developed by Fried, we compared the frail and non-frail groups. Poor physical performance assessed with the short physical performance battery score of $<9$ is considered frailty. To evaluate the relationship between the variables, simple and fully adjusted multivariable logistic regression analyses were performed according to sex.

Results

Among the participants, 462 (19.3\%) were defined as the frail group, with a significantly high mean age of $77.9 \pm 4.0$ years. In the logistic regression analysis of frailty based on body mass index (BMI) categories, underweight $\left(\mathrm{BMK}<18 \mathrm{~kg} / \mathrm{m}^{2}\right)$ participants showed a high incidence of frailty in both sexes. BMI showed an association with frailty only in males. In both sexes, FFMI was associated with a lower incidence of frailty, which was statistically significant in the fully adjusted models. In the female, fat-related indexes including body fat percentage, FMI, and TFMI showed a significant association with poor physical performance. In contrast, males with low FFMI only showed a significant association with poor physical performance.

\section{Conclusions}

Frailty closely correlated with FFMI in both sexes. The poor physical performance associated with frailty correlated with fat-related body composition in females and fat-free mass in males owing to the difference in body composition between the sexes. In the assessment of frailty, body composition and sex-related differences should be analyzed.

\section{Background}

Frailty is a common geriatric condition due to aging, defined as muscle weakness and a decrease in the physiological ability to maintain homeostasis, that increases the risk of adverse health outcomes such as 
procedural complications, hospitalization, falls, disability, and death.[1, 2] Although aging is the major cause of frailty, other associated factors, including lower educational level, smoking, alcohol, being single, ethnicity, depression, lack of exercise, poor nutrition, chronic comorbidities, intellectual disability, and social isolation, were reported.[3-5] According to a systematic review based on 21 cohort studies of 61,500 participants, the prevalence of frailty in the community-dwelling elderly ranged from $4.0 \%$ to $59.1 \%$, depending on the frailty criteria and study population. An average of $10.7 \%$ of the participants aged $>65$ years were defined as frailty.[6]

Owing to prolonged life expectancy and an increased elderly population, the prevalence of frailty was also increased with aging.[7] The prevalence rates of frailty were $3.2 \%, 5.3 \%, 9.5 \%, 16.3 \%, 25.7 \%$, and $23 \%$ in the 65- to 70-, 71- to 74-, 75- to 79-, 80- to 85-, 86- to 90-, and >90-year age groups, respectively.[7] Previous studies revealed that the implementation of exercise programs and nutritional supplementation might reverse or prevent frailty. Therefore, identifying and preventing frailty are crucial issues from the public health perspective because frail elderly are in need extra medical attention and substantial socioeconomic costs.[8]

Obesity prevalence increases after middle age, but its prevalence differs according to sex in the elderly population.[9] Recent data from Korea indicated that the prevalence of obesity among males was $37.8 \%$ in the 50 - to 60 -year age group and $39.7 \%$ in the 60 - to 70 -year age group, but decreased to $30.3 \%$ in the $>70$-year age group. By contrast, in females, the prevalence rate was $32.5 \%$ in the 50 - to 60 -year age group, $40.7 \%$ in the 60 - to 70 -year age group, and $42.2 \%$ in the $>70$-year age group, showing increases with age. $[10,11]$ This is because female elderly have less essential metabolism and energy consumption than male elderly, and the higher the age, the more easily fat accumulates. With aging, muscles decrease, and fat tissue increases.[12] A decrease in muscle and an increase in fat mass can occur without total weight change.[13] Indeed, according to a 10-year prospective study in the elderly with an initial age of 60.7 years, males showed a $1.2-\mathrm{kg}$ gain in body fat without changes in body weight, and females showed 1.2-kg body weight increase, mostly fat mass.[14] The body composition changes due to aging are characterized by the accumulation of fat in the abdominal cavity, liver, and especially intra-muscle.[15] Therefore, when studying obesity in the elderly population, not only body mass index (BMI) but also body composition and sex-related differences must be examined. As body composition changes with aging, increased both body mass index (BMI), representing weight per height in meter squared, and body composition are necessary as diagnostic criteria for obesity in the elderly.[16]

The decreased or increased BMI affecting on frailty has been studied, decreased BMI is associated with a decrease in skeletal muscle mass due to aging.[17] And an increase in BMI as obesity causes increased deposition of lipid within muscle fibers with aging, and lipid infiltration contributes to reduced muscle strength.[18] Based on the literature, the correlation between frailty and BMI, and the results were controversial. A study that used data from the National Health and Nutrition Survey, aged $\geq 60$ years, showed that BMI was higher in frail participants. [19] Still, a recent study in China, aged $>65$ years, showed that underweight participants with a BMI of $<18.5 \mathrm{~kg} / \mathrm{m}^{2}$ had a high risk of frailty, but obesity $\geq 30 \mathrm{~kg} / \mathrm{m}^{2}$ did not increase the risk of frailty.[20] With height decreased and body composition changes in old age. 
Recent studies also showed that $\mathrm{BMI}$ alone is not an adequate measurement of underlying changes in fat-free mass (FFM) and body fat mass during aging. Fat mass index (FMI), trunk fat mass index (TFMI), FFM index (FFMI), and body fat percentage (BFP) are useful parameters for evaluating body composition by effectively eliminating differences in height.[21, 22]

The present cross-sectional study investigated the relationship between body composition including FMI, FFMI, BFP, and frailty in community-dwelling elderly Koreans. Although no gold standard for the diagnosis of frailty has been established, the cardiovascular health study (CHS) frailty index by Fried is the most cited and widely used for risk assessment and epidemiological studies. The short physical performance battery (SPPB) is a useful screening tool for identifying decreased physical performance. We hypothesized that correlations exist among frailty, poor physical performance, and body composition parameters.

\section{Methods}

\section{Data and study population}

By using data from 2016 to 2017 of the Korean Frailty and Aging Cohort Study (KFACS), we investigated the association between frailty and body composition in community-dwelling elderly aged between 70 and 84 years. The goal of the KFACS was to conduct a nationwide study in Korea to identify the prevalence and prevent frailty in community dwellers.[23] Participants were recruited from diverse circumstances, including housing complexes, community welfare or health centers, and outpatient clinics to minimize selection bias. All participants were informed of the use of the data for research in this study. Among the 3,014 participants, those with severe dementia with a Mini-Mental State Examination in the Korean version (MMSE-KC) score of $<9$, Parkinson's disease, history of cerebrovascular and cardiopulmonary diseases, inability to complete the frailty questionnaire and SPPB test, and no dualenergy X-ray absorptiometry (DXA) data, were excluded (a total of 629 participants). From 10 centers, including eight hospitals and two public health centers in South Korea, 2,385 participants (1,131 men and 1,254 women) were recruited. Trained researchers individually interviewed and tested the participants. The sociodemographic data collected included age, sex, years of education $(<6,7-12$, and $>13$ years), marital status, monthly income $(<1,1-3$, and $>3$ million Korean won; 1 million won is approximately 900 US dollars), and location of residence (urban or rural). Personal habits such as smoking ( $>1$ cigarette per week) and alcohol (at least once a week) were also recorded. Chronic comorbidities that affect metabolic syndrome, including hypertension, diabetes mellitus, dyslipidemia, and musculoskeletal diseases such as osteoarthritis, osteoporosis, and depression, were also evaluated. All the cohort data that support the findings of this study are available from KFACS and open to all researchers upon reasonable research requests. All published articles and news articles using the KFACS database, data provision manuals, and contact information are available at the KFACS website (http://www.kfacs.kr). The KFACS study protocol was approved by the Institutional Review Board of the Clinical Research Ethics Committee of Kyung-Hee University Medical Center, and all the participants provided written informed consent (IRB No. 2015-12103). 


\section{Frailty}

Although there is no gold standard for diagnosis as frailty, the CHS frailty index by Fried is the most cited and widely used for risk assessment and epidemiological studies. The Short Physical Performance Battery(SPPB) is a useful screening tool for identifying decreased physical performance.

CHS frailty scale To identify frailty, we used the modified Korean version of the CHS frailty scale by Fried. $[24,25]$ The validity and reliability of the Korean version of the CHS frailty scale did not differ from the CHS frailty score.[26] The CHS frailty scale is widely used and the most cited frailty scale and is useful for screening and identifying frailty.[7] It is composed of a questionnaire with five components, namely unintentional weight loss, weakness, exhaustion, slowness of walking speed, and reduced physical activity level. Frailty was confirmed if $\geq 3$ of the five components were fulfilled. (1) Weight loss was defined as an unintentional weight loss of $>4.5 \mathrm{~kg}$ or $5 \%$ of the body weight in the previous year. (2) Weakness was measured as the handgrip strength (HGS) on both sides, twice on each side, in a sitting position. The highest value was assessed by using a hand dynamometer (JAMAR, Bolingbrook, IL, USA). Weakness was defined as a decreased HGS to $<26 \mathrm{~kg}$ for men and $<18 \mathrm{~kg}$ for women. (3) Exhaustion was defined when the participants were asked, "Did you feel hard about everything?" or "Did you feel that you can't do anything?" and answered $\geq 3$ days per week. (4) Reduced walking speed was defined as a walking speed of $<1 \mathrm{~m} / \mathrm{s}$ measured twice over a 4-m walking distance at the usual pace. (5) Reduced physical activity was defined as a low-calorie consumption for a week calculated according to sex (<494.65 kcal for men and $<283.50 \mathrm{kcal}$ for women) based on the short-term International Physical Activity Questionnaire.

Physical performance The SPPB is a useful screening tool for identifying poor physical performance and frailty syndrome in the elderly population.[27] The SPPB score only objectively measures lower limb physical performance but also is highly associated with adverse health outcomes such as fall risk, disability, and mortality, even in high-functioning older adults.[28] It consists of three tests, including standing balance, gait speed in a 4-m walk, and a timed test of 5 repeated chair stands. Each test is scored from 0 to 4 . Adding the scores in the 3 categories, the total score ranges from 0 to 12, and a higher score indicates better physical performance.[29] In previous studies, SPPB scores of $\leq 9$ showed $81-92 \%$ sensitivity and $52-80 \%$ specificity for identifying frailty and were associated with an increased risk of allcause mortality.[28, 30] Thus, these cutoff points were used to classify the participants with poor physical performance.

\section{Body composition}

The participants' height and weight were measured. BMI was calculated as body weight in kilograms divided by the height in square meters (total body weight $[\mathrm{kg}] /$ height $[\mathrm{m}]^{2}$ ). Body compositions, including total and trunk fat masses and FFM, were measured by DXA (GE Medical Systems Lunar, Madison, WI, USA). FMI and TFMI were calculated as the total fat mass and trunk fat mass according to height squared, respectively (fat mass $[\mathrm{kg}] /$ height $[\mathrm{m}]^{2}$ ). $[21,31] \mathrm{FFMI}$ was calculated as the total weight except 
for the total fat mass, divided by height squared (FFM [kg]/height $\left.[\mathrm{m}]^{2}\right)$. [22] Body fat percentage (BFP) is the total mass of fat divided by total body weight multiplied by 100 .

\section{Statistical analyses}

The demographic characteristics were analyzed on the basis of the frail and non-frail groups of participants. The Student $t$ test was used for the continuous variables (height, weight, BFP, BMI, FMI, TFMI, FFMI, WBC, $\mathrm{Hb}$, and MMSE-KC) and the chi-square test, for the categorical covariables (BMI categories, years of education, marital status, income per month, location of residence, smoking, alcohol, and comorbidities). The results are presented as mean \pm standard deviation (SD) or numbers (\%) according to the characteristics of the variables. Univariate and multivariate analyses were performed using logistic regression models and used to evaluate the odds ratio (OR). The analyses were used to examine the associations between BMI, each body composition as an independent variable, and frailty as the dependent variable. Multivariate logistic regression analyses were fully adjusted for multiple correlations between frailty and other potential confounders. Potential confounding variables such as age, years of education, location of residence, depression, marital status, monthly income, and metabolic syndrome comorbidities, including diabetes mellitus, dyslipidemia, hypertension, and musculoskeletal diseases were fully adjusted in the multiple regression analysis. The same analyses were repeated using $\mathrm{BMI}, \mathrm{FMI}, \mathrm{TFMI}$, and FFMI as covariates. As each body composition parameter showed multicollinearity, with a variance inflation factor (VIF) value of $>10$, the parameters were analyzed separately. Coefficients were indicated as $95 \%$ confidence intervals $(\mathrm{Cls})$. As body composition differs significantly between the sexes, the statistical data were divided into sex groups. The collected data were analyzed using IBM SPSS Statistics version 23.0 for Windows (IBM Corp., Armonk, NY). P values of <.05 were considered statistically significant.

\section{Results}

Table 1 shows the baseline characteristics of the participants based on frailty. Among the participants, 462 (19.3\%) were defined as the frail group according to the Fried frailty criteria, and 1923 (80.7\%) who showed robustness or pre-frailty were defined as the non-frail group. The mean age of the total participants was $76.4 \pm 3.8$ years and was significantly higher in the frail group ( $77.9 \pm 4.0$ years). The total fat mass, FFMI, and BMI were significantly lower in the frail group, but no significant differences in BFP and FMI were found between the groups. The demographic data of the frail group showed lower number of years of education, income, and MMSE scores $(P<.001)$. On the basis of the BMI categories, the frail group showed a high proportion of underweight participants $(P<.001)$.

Baseline body compositions of participants based on sex are presented in Table 2. BMI and fat massrelated indexes including BFP, FMI, and TFMI, total fat mass, and trunk fat mass were significantly higher in females $(P<.001)$ whereas FFMI was higher in males $(P<.001)$. 
Table 3 shows the univariate and multivariate logistic regression analyses of frailty according to $\mathrm{BMI}$ category. On the basis of normal weight (BMI of $\left.18-25 \mathrm{~kg} / \mathrm{m}^{2}\right)$ as a reference, the underweight $(\mathrm{BMI}<18$ $\mathrm{kg} / \mathrm{m}^{2}$ ) participants showed a higher incidence of frailty in both sexes. After adjusting for the confounding factors such as age, alcohol, smoking habit, monthly income, years of education, hypertension, diabetes, dyslipidemia, and depression, the correlation was still significant in males and females (OR, 2.92; 95\% Cl, 1.39-6.15 and OR, 2.80; 95\% Cl, 0.70-8.07, respectively). The results of the unadjusted and fully adjusted logistic regression analyses of poor physical performance (SPPB score $\leq$ 9) based on BMI categories did not show any statistical correlation with the BMI categories in both sexes (data not shown).

Table 4 shows the univariate and multivariate logistic regression analyses of frailty according to $\mathrm{BMI}$ and body composition parameters. In males, BMI was associated with an incidence of frailty, which was statistically significant in the unadjusted and fully adjusted models (OR, $0.926 ; 95 \% \mathrm{Cl}, 0.880-0.975 \mathrm{vs}$ OR, 0.914; $95 \% \mathrm{Cl}, 0.864-0.967)$. Moreover, in males, FFMls showed an association with incidence of frailty in the unadjusted and fully adjusted models (OR, $0.808 ; 95 \% \mathrm{Cl}, 0.737-0.885$ vs OR, $0.812 ; 95 \% \mathrm{Cl}$, 0.736-0.896). In females, FFMI correlated with an incidence of frailty in the fully adjusted model (OR, $0.891 ; 95 \% \mathrm{Cl}, 0.798-0.995)$ but not in the unadjusted model. The other body composition parameters including BFP, FMI, and TFMI showed no significant correlations in both sexes.

Table 5 shows the univariate and multivariate logistic regression analyses of poor physical performance (SPPB score $\leq 9$ ) according to body composition parameters. In males, FFMI showed an association with incidence of poor physical performance in the unadjusted and fully adjusted models $(\mathrm{OR}, 0.836 ; 95 \% \mathrm{Cl}$, $0.748-0.935$ vs OR, $0.865 ; 95 \% \mathrm{Cl}, 0.767-0.974)$. In females, the fat-related indexes including $\mathrm{BMI}(\mathrm{OR}$, 1.058; 95\% Cl, 1.008-1.111), BFP (OR, 1.034; 95\% Cl, 1.008-1.061), FMI (OR, 1.090; 95\% Cl, 1.023$0.161)$, and TFMI (OR, 1.121; $95 \% \mathrm{Cl}, 1.014-1.240)$ showed an association with incidence rates of poor physical performance in the fully adjusted models but not FFMI.

\section{Discussion}

The results of this study showed that the difference in body composition between the sexes influenced frailty and poor physical performance. Body composition was mainly divided into two components, fatrelated mass and FFM. In this study, frailty was related to FFMI in both sexes. FFM was composed of skeletal muscle mass, body cell mass, total body water, and bone mineral mass, and used to compare skeletal muscle mass, which is a major component of FFM.[32] Our results showed that among the body components, skeletal muscle mass is closely related to frailty. However, in the case of BMI, males showed a high incidence of frailty as BMI decreased, whereas females showed no statistically significant incidence of frailty in relation to BMI. This result coincides with a report that unintentional weight loss out of frailty component was more incident in males.[33]

For poor physical performance, high BMI and the fat-related indexes BFP, FMI, FFMI, and TFMI were found to be statistically relevant in the females. In males, high FFMI lowered the incidence of poor physical 
performance. This means that the body compositions of males and females affect physical performance differently. This could be explained by several reasons. With aging, the change in body composition appears differently between the sexes. In males, the FFM peaks in the mid-30s, but in females, FFM is stable until around the age of 50 years and then decreases thereafter.[34] In the elderly, females have a trend of more easily accumulating fat because of the low essential metabolism and energy consumption than males. Moreover, after menopause, because of the decreases in the levels of the sex hormones, skeletal muscles decrease and fat mass increases.[35] In males with early age skeletal mass reduction, maintenance of skeletal mass had a more significant effect on frailty in the elderly.[34] Nevertheless, in a fully adjusted model, both sexes showed a statistically significant FFMI, which reflects that among the body compositions, FFM is the most critical factor of frailty.

In the previous studies, the relationship between obesity defined by BMI and frailty was investigated, but results were controversial. In a cross-sectional analysis of community-dwelling women aged 70 to 79 years, an obesity BMI of $>30 \mathrm{~kg} / \mathrm{m}^{2}$ was significantly associated with frailty even when adjusted for covariates (OR, 3.52; 95\% Cl, 1.34-9.13).[36] In a longitudinal study in Spain with 3.5 years of follow-up, among the 287 participants aged $>65$ years, general obesity and the risk of frailty were significantly associated (OR, 1.73; 95\% Cl, 1.18-2.28).[37] In another study, the correlation between BMI and frailty showed a U-shaped curve in 3,055 community-dwelling adults aged $>65$ years. The subjects with BMls of $<20 \mathrm{~kg} / \mathrm{m}^{2}$ and $\geq 30 \mathrm{~kg} / \mathrm{m}^{2}$ showed higher frailty incidence rates.[38] However, in other studies in Asia, the correlation between obesity and frailty was not clear. According to a recent study in China that evaluated participants aged $\geq 65$ years, body composition and frailty were correlated. Underweight groups $(\mathrm{BMI}<$ $18.5 \mathrm{~kg} / \mathrm{m}^{2}$ ) showed higher frailty incidence rates (OR, 4.146; 95\% Cl, 1.286-13.368).[20] Lee et al. evaluated 11,844 Koreans aged $\geq 65$ years, and compared to the normal weight group, the underweight group showed a higher incidence rate of frailty $(\mathrm{OR}, 2.52 ; 95 \% \mathrm{Cl}, 1.72-3.69)$, but no statistically significant difference was found between normal weight and the other overweight and obesity groups. [39] This result is consistent with our findings that the risk of frailty increases in underweight subjects with BMls of $\leq 18.5 \mathrm{~kg} / \mathrm{m}^{2}$. Controversial results among the studies could be due to differences in population and ethnicity. The results that indicated no correlation between obesity and frailty could be explained by a relatively low obesity rate in Asians. The proportion of BMls of $>30 \mathrm{~kg} / \mathrm{m}^{2}$ in an east Asian study was $3-5 \%$, but in a Western study, it was $26.5 \%$.[38] Therefore, in Asians, obesity defined by BMI is not adequate for predicting frailty.

The aging process results in body composition changes as fat mass increases and muscle mass decreases; thus, BMI does not accurately represent obesity in the elderly population.[40] Therefore, in our study, fat mass-related parameters using total and trunk fat mass and fat-free mass, and obesity by BMI were used. In a study in Brazil with 235 elderly subjects aged $>65$ years, the frailty group of elderly subjects was characterized by lower muscle mass and higher BFP.[41] In China, Xu et al. reported that the groups with high body fat mass showed higher frailty incidence rates $(\mathrm{OR}, 1.143 ; 95 \% \mathrm{Cl}, 0.892-1.315)$, and those with a higher skeletal muscle mass had a lower risk of frailty after fully adjustment of the confounding factors $(\mathrm{OR}, 0.159 ; 95 \% \mathrm{Cl}, 0.064-0.396)$.[20] These results are consistent with our result 
that frailty correlates with FFMI, which represents skeletal muscle mass. Skeletal muscle mass is important especially in the elderly population. Loss of skeletal muscle mass is a result of sarcopenia due to aging, cachexia due to chronic disease, or atrophy due to inactivity.[42] All of these causes could be risk factors of frailty. Weight loss is one of the frailty criteria by Fried, and the reduction in skeletal mass in the elderly population leads to weight loss, which increases the risk of frailty in the underweight population. The linear logistic analysis revealed that lower BMI increased the frailty incidence only in males. The proportion of FFM, which is reflected in BMI, was relatively higher in males than in females. By contrast, in females, the proportion of fat-related mass was relatively high, so the increase or decrease in FFM was not fully reflected in BMI.

In the present study, we analyzed the groups with SPPB scores of $\leq 9$, which defines poor physical performance, and several results were meaningful. Unlike the frailty index, the BMI categories for analyzing poor physical performance showed no statistically significant differences. However, the logistic regression analysis revealed meaningful results, and in males, the physical frailty risk was low when the FFMI, which reflects skeletal muscle mass, was high. In females, the fat-related indexes BMI, BFP, FMI, and TFMI were statistically significant in a fully adjusted model. FFM in males and the fat-related index in females affected physical performance, and the previous results showed a similar pattern. In a study that involved 1821 participants ( $65 \%$ female) in the United States, among the muscle mass parameters, fat mass and SPBB score were studied. Increased BMI and BFP were associated with lower SPPB scores, and the appendicular muscle mass showed a higher SPPB score.[43] Torres et al. evaluated 217 Mexican subjects (65.4\% females) aged $>60$ years and found associations among FFMI, FMI, and poor physical performance based on SPPB scores.[44] Poor physical performance significantly correlated with FMI but not with FFMI. Owing to the relatively high rate of females in these studies, the results were consistent with our results for females. Our results showed significant differences between the sexes. Additional research is needed on the sex difference in physical performance according to the body composition.

This study has several limitations. First, because this study was a cross-sectional analysis, we could not evaluate longitudinal effect of body compositions on frailty or physical performance according to longterm changes in body composition. However, this large cohort with $>1,000$ participants of each sex is still meaningful. Further prospective studies are warranted to strengthen our findings. Second, we could not measure estradiol levels. This factor may intervene the relation between fat mass and physical performances.[45-47] In postmenopausal women, higher endogenous estradiol level was associated with frailty.[48] However, we could not measure the estradiol levels. This factor may link the correlation between fat mass and sex hormone; therefore, further research is needed. Third, this study did not evaluate nutrition status and polypharmacy, which both affect frailty.[49] However, this limitation was somewhat attenuated because this study adjusted for the confounding comorbidity that causes metabolic syndrome and musculoskeletal problems.

\section{Conclusion}


This cross-sectional study investigated the association of body composition with frailty and poor physical performance in a community-dwelling elderly population aged $>70$ years. Owing to the differences in body composition characteristics between the sexes, each sex was analyzed separately. To our knowledge, this is the first large-scale cohort study in Asia that included $>1,000$ participants of each sex. Furthermore, previous studies measured fat mass by skinfold thickness and body impedance analysis, which are less accurate than DXA. This study measured not only BMI but also body composition including BFP, FMI, TFMI, and FFMI. Our results showed that frailty was closely correlated with FFMI in both sexes. The SPPB scale score, which was used to evaluate physical performance, revealed that poor physical performance associated with frailty was only associated with fat-related body composition in females. In males, only FFMI was associated with poor physical performance. This is considered to be the result of the difference in body composition between males and females. For assessing frailty, body composition and sex-related differences should be analyzed. Further study is needed to clarify the correlations between fat mass and the levels of sex hormones that affect frailty.

\section{Abbreviations}

KFACS: Korean Frailty and Aging Cohort Study; CHS: cardiovascular health study; BMI: body mass index; BFP: body fat percentage; FMI: fat mass index; FFMI: fat-free mass index; TFMI: trunk fat mass index; SPPB: short physical performance battery

\section{Declarations}

\section{Ethics approval and consent to participate}

The KFACS study protocol was approved by the Institutional Review Board of the Clinical Research Ethics Committee of Kyung-Hee University Medical Center, and all the participants provided written informed consent (IRB No. 2015-12-103).

\section{Consent for publish}

There are no details of individual participants in the manuscript.

\section{Availability of data and materials}

All the cohort data that support the findings of this study are available from KFACS and open to all researchers upon reasonable research requests. All published articles and news articles using the KFACS database, data provision manuals, and contact information are available at the KFACS website (http://www.kfacs.kr).

\section{Competing interests}

The authors have no competing interests to declare. 


\section{Funding}

This study was supported by a grant from the Korea Health Technology R\&D Project through the Korean Health Industry Development Institute (KHIDI), funded by the Ministry of Health \& Welfare, Republic of Korea (grant number: HI15C3153 and HI15C3207).

\section{Authors' contributions}

YS and CWW were involved in designing the study. YS and CWW contributed to the analysis and manuscript. YS and CWW reviewed the study overall and performed significant editing of the manuscript. The authors have read and approved the final manuscript.

\section{Acknowledgments}

The authors are grateful to the study participants and the staff of the Korean Frailty and Aging Cohort Study, which was the primary source of our study. We would like to thank Editage (www.editage.co.kr) for English language editing.

\section{References}

1. Chen $\mathrm{C}-\mathrm{Y}, \mathrm{Wu} \mathrm{S}-\mathrm{C}$, Chen $\mathrm{L}-\mathrm{J}, \mathrm{Lue} \mathrm{B}-\mathrm{H}$ : The prevalence of subjective frailty and factors associated with frailty in Taiwan. Archives of gerontology and geriatrics 2010, 50:S43-S47.

2. Milte R, Crotty M: Musculoskeletal health, frailty and functional decline. Best Practice \& Research Clinical Rheumatology 2014, 28(3):395-410.

3. Woods NF, LaCroix AZ, Gray SL, Aragaki A, Cochrane BB, Brunner RL, Masaki K, Murray A, Newman $A B$ : Frailty: emergence and consequences in women aged 65 and older in the Women's Health Initiative Observational Study. Journal of the American Geriatrics Society 2005, 53(8):1321-1330.

4. Bandeen-Roche K, Seplaki CL, Huang J, Buta B, Kalyani RR, Varadhan R, Xue Q-L, Walston JD, Kasper JD: Frailty in older adults: a nationally representative profile in the United States. The Journals of Gerontology: Series A 2015, 70(11):1427-1434.

5. Lakey SL, LaCroix AZ, Gray SL, Borson S, Williams CD, Calhoun D, Goveas JS, Smoller JW, Ockene JK, Masaki KH: Antidepressant Use, Depressive Symptoms, and Incident Frailty in Women Aged 65 and Older from the W omen's H ealth I nitiative Observational Study. Journal of the American Geriatrics Society 2012, 60(5):854-861.

6. Collard RM, Boter H, Schoevers RA, Oude Voshaar RC: Prevalence of frailty in community-dwelling older persons: a systematic review. Journal of the American Geriatrics Society 2012, 60(8):14871492.

7. Fried LP, Ferrucci L, Darer J, Williamson JD, Anderson G: Untangling the concepts of disability, frailty, and comorbidity: implications for improved targeting and care. The Journals of Gerontology Series A: Biological Sciences and Medical Sciences 2004, 59(3):M255-M263. 
8. Hazra NC, Rudisill C, Gulliford MC: Determinants of health care costs in the senior elderly: age, comorbidity, impairment, or proximity to death? The European Journal of Health Economics 2018, 19(6):831-842.

9. Inelmen EM, Sergi G, Coin A, Miotto F, Peruzza S, Enzi G: Can obesity be a risk factor in elderly people? Obesity reviews 2003, 4(3):147-155.

10. Hales CM, Carroll MD, Fryar CD, Ogden CL: Prevalence of obesity among adults and youth: United States, 2015-2016. 2017.

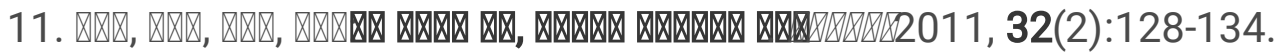

12. St-Onge M-P, Gallagher D: Body composition changes with aging: the cause or the result of alterations in metabolic rate and macronutrient oxidation? Nutrition 2010, 26(2):152-155.

13. Thomas DR: Loss of skeletal muscle mass in aging: examining the relationship of starvation, sarcopenia and cachexia. Clinical nutrition 2007, 26(4):389-399.

14. Hughes T, Borenstein A, Schofield E, Wu Y, Larson E: Association between late-life body mass index and dementia: The Kame Project. Neurology 2009, 72(20):1741-1746.

15. Ponti F, Santoro A, Mercatelli D, Gasperini C, Conte M, Martucci M, Sangiorgi L, Franceschi C, Bazzocchi A: Aging and imaging assessment of body composition: from fat to facts. Frontiers in Endocrinology 2019, 10:861.

16. Ritz P: Obesity in the elderly: should we be using new diagnostic criteria? The journal of nutrition, health \& aging 2009, 13(3):168.

17. Stoever K, Heber A, Eichberg S, Brixius K: Sarcopenia and predictors of skeletal muscle mass in elderly men with and without obesity. Gerontology and Geriatric Medicine 2017, 3:2333721417713637.

18. Starr KNP, McDonald SR, Bales CW: Obesity and physical frailty in older adults: a scoping review of lifestyle intervention trials. Journal of the American Medical Directors Association 2014, 15(4):240250 .

19. Crow RS, Lohman MC, Titus AJ, Bruce ML, Mackenzie TA, Bartels SJ, Batsis JA: Mortality risk along the frailty spectrum: data from the National Health and Nutrition Examination Survey 1999 to 2004. Journal of the American Geriatrics Society 2018, 66(3):496-502.

20. Xu L, Zhang J, Shen S, Hong X, Zeng X, Yang Y, Liu Z, Chen L, Chen X: Association Between Body Composition and Frailty in Elder Inpatients. Clinical Interventions in Aging 2020, 15:313.

21. Schutz Y, Kyle U, Pichard C: Fat-free mass index and fat mass index percentiles in Caucasians aged 18-98 y. International journal of obesity 2002, 26(7):953-960.

22. Kyle UG, Schutz Y, Dupertuis YM, Pichard C: Body composition interpretation: contributions of the fatfree mass index and the body fat mass index. Nutrition 2003, 19(7-8):597-604.

23. Won CW, Lee Y, Choi J, Kim KW, Park Y, Park H, Oh IH, Ga H, Kim YS, Jang HC: Starting construction of frailty cohort for elderly and intervention study. Annals of Geriatric Medicine and Research 2016, 20(3):114-117. 
24. Fried LP, Tangen CM, Walston J, Newman AB, Hirsch C, Gottdiener J, Seeman T, Tracy R, Kop WJ, Burke G: Frailty in older adults: evidence for a phenotype. The Journals of Gerontology Series A: Biological Sciences and Medical Sciences 2001, 56(3):M146-M157.

25. Hwang HS, Kwon IS, Park BJ, Cho B, Yoon JL, Won CW: The validity and reliability of Korean frailty index. Journal of the Korean Geriatrics Society 2010, 14(4):191-202.

26. Jung H-W, Yoo H-J, Park S-Y, Kim S-W, Choi J-Y, Yoon S-J, Kim C-H, Kim K-i: The Korean version of the FRAIL scale: clinical feasibility and validity of assessing the frailty status of Korean elderly. The Korean journal of internal medicine 2016, 31(3):594.

27. Perracini MR, Mello M, de Oliveira Máximo R, Bilton TL, Ferriolli E, Lustosa LP, da Silva Alexandre T: Diagnostic Accuracy of the Short Physical Performance Battery for Detecting Frailty in Older People. Physical therapy 2020, 100(1):90-98.

28. Pavasini R, Guralnik J, Brown JC, Di Bari M, Cesari M, Landi F, Vaes B, Legrand D, Verghese J, Wang C: Short physical performance battery and all-cause mortality: systematic review and meta-analysis. BMC medicine 2016, 14(1):215.

29. Guralnik JM, Simonsick EM, Ferrucci L, Glynn RJ, Berkman LF, Blazer DG, Scherr PA, Wallace RB: A short physical performance battery assessing lower extremity function: association with selfreported disability and prediction of mortality and nursing home admission. Journal of gerontology 1994, 49(2):M85-94.

30. da Câmara SMA, Alvarado BE, Guralnik JM, Guerra RO, Maciel ÁCC: Using the Short Physical Performance Battery to screen for frailty in young-old adults with distinct socioeconomic conditions. Geriatrics \& gerontology international 2013, 13(2):421-428.

31. Kim JH, Chon J, Soh Y, Han YR, Won CW, Lee SA: Trunk fat mass correlates with balance and physical performance in a community-dwelling elderly population: Results from the Korean Frailty and aging cohort study. Medicine 2020, 99(9):e19245.

32. Wells J, Fewtrell M: Measuring body composition. Archives of disease in childhood 2006, 91(7):612617.

33. Alexandre TdS, Corona LP, Brito TR, Santos JL, Duarte YA, Lebrao ML: Gender differences in the incidence and determinants of components of the frailty phenotype among older adults: findings from the SABE Study. Journal of aging and health 2018, 30(2):190-212.

34. Joseph LJ, Ryan AS: Body Weight, Body Composition, and Aging. 2004.

35. Wu BN, O'Sullivan AJ: Sex differences in energy metabolism need to be considered with lifestyle modifications in humans. Journal of nutrition and metabolism 2011, 2011.

36. Blaum CS, Xue QL, Michelon E, Semba RD, Fried LP: The association between obesity and the frailty syndrome in older women: the Women's Health and Aging Studies. Journal of the American Geriatrics Society 2005, 53(6):927-934.

37. García-Esquinas E, José García-García F, León-Muñoz LM, Carnicero JA, Guallar-Castillón P, Gonzalez-Colaço Harmand M, López-García E, Alonso-Bouzón C, Rodríguez-Mañas L, Rodríguez- 
Artalejo F: Obesity, fat distribution, and risk of frailty in two population-based cohorts of older adults in S pain. Obesity 2015, 23(4):847-855.

38. Hubbard RE, Lang IA, Llewellyn DJ, Rockwood K: Frailty, body mass index, and abdominal obesity in older people. Journals of Gerontology Series A: Biomedical Sciences and Medical Sciences 2010, 65(4):377-381.

39. Lee Y, Kim J, Han ES, Ryu M, Cho Y, Chae S: Frailty and body mass index as predictors of 3-year mortality in older adults living in the community. Gerontology 2014, 60(6):475-482.

40. Batsis JA, Mackenzie TA, Bartels SJ, Sahakyan KR, Somers VK, Lopez-Jimenez F: Diagnostic accuracy of body mass index to identify obesity in older adults: NHANES 1999-2004. International journal of obesity 2016, 40(5):761-767.

41. Villareal DT, Banks M, Siener C, Sinacore DR, Klein S: Physical frailty and body composition in obese elderly men and women. Obesity research 2004, 12(6):913-920.

42. Evans WJ: Skeletal muscle loss: cachexia, sarcopenia, and inactivity. The American journal of clinical nutrition 2010, 91(4):1123S-1127S.

43. Kim S, Leng XI, Kritchevsky SB: Body composition and physical function in older adults with various comorbidities. Innovation in aging 2017, 1(1).

44. Torres MR, Valenzuela RER, Esparza-Romero J, Teros MTL, Alemán-Mateo H: The fat mass index, not the fat-free mass index, is associated with impaired physical performance in older adult subjects: Evidence from a cross-sectional study. Clinical Nutrition 2019, 38(2):877-882.

45. Colleluori G, Chen R, Napoli N, Aguirre LE, Qualls C, Villareal DT, Armamento-Villareal R: Fat mass follows a U-shaped distribution based on estradiol levels in postmenopausal women. Frontiers in endocrinology 2018, 9:315.

46. Marchand GB, Carreau A-M, Weisnagel SJ, Bergeron J, Labrie F, Lemieux S, Tchernof A: Increased body fat mass explains the positive association between circulating estradiol and insulin resistance in postmenopausal women. American Journal of Physiology-Endocrinology and Metabolism 2018, 314(5):E448-E456.

47. Gates MA, Mekary RA, Chiu GR, Ding EL, Wittert GA, Araujo AB: Sex steroid hormone levels and body composition in men. The Journal of Clinical Endocrinology \& Metabolism 2013, 98(6):2442-2450.

48. Carcaillon L, Garcia-Garcia F, Tresguerres J, Gutierrez Avila G, Kireev R, Rodríguez-Mañas L: Higher levels of endogenous estradiol are associated with frailty in postmenopausal women from the toledo study for healthy aging. The Journal of Clinical Endocrinology \& Metabolism 2012, 97(8):2898-2906.

49. Bonaga B, Sánchez-Jurado PM, Martínez-Reig M, Ariza G, Rodríguez-Mañas L, Gnjidic D, Salvador T, Abizanda P: Frailty, polypharmacy, and health outcomes in older adults: the frailty and dependence in Albacete study. Journal of the American Medical Directors Association 2018, 19(1):46-52.

\section{Tables}

Table 1. Baseline characteristics of participants by frailty status 


\begin{tabular}{|c|c|c|c|c|c|}
\hline \multirow[t]{2}{*}{ Characteristic } & & Non-frail & Frail & Total & \multirow[t]{2}{*}{$\mathbf{P}$} \\
\hline & & $(n=1923)$ & $(n=462)$ & $(n=2385)$ & \\
\hline Age (mean $\pm S D)$ & & $76.13 \pm 3.7$ & $77.9 \pm 4.0$ & $76.4 \pm 3.8$ & $<.001 *$ \\
\hline Female, n (\%) & & $1013(52.7)$ & $241(52.2)$ & $1254(52.6)$ & .843 \\
\hline Height, cm (mean \pm SD) & & $158.3 \pm 8.3$ & $156.7 \pm 8.8$ & $158.0 \pm 8.4$ & $<.001 *$ \\
\hline Weight, kg (mean \pm SD) & & $61.5 \pm 9.2$ & $59.1 \pm 9.8$ & $61.0 \pm 9.3$ & $<.001 *$ \\
\hline Total fat mass, $\mathrm{kg}$ (mean $\pm \mathrm{SD}$ ) & & $19.7 \pm 5.7$ & $19.1 \pm 6.2$ & $19.6 \pm 5.8$ & $.041 *$ \\
\hline Trunk fat mass, kg (mean \pm SD) & & $10.9 \pm 3.5$ & $10.4 \pm 3.7$ & $10.7 \pm 3.6$ & $.002 *$ \\
\hline $\mathrm{BMI}, \mathrm{kg} / \mathrm{m}^{2}($ mean $\pm \mathrm{SD})$ & & $\begin{array}{l}24.49 \pm \\
2.91\end{array}$ & $\begin{array}{l}24.03 \pm \\
3.27\end{array}$ & $\begin{array}{l}24.40 \pm \\
2.99\end{array}$ & $.003^{*}$ \\
\hline $\mathrm{BFP}, \%($ mean $\pm \mathrm{SD})$ & & $32.17 \pm 7.8$ & $32.15 \pm 8.3$ & $32.1 \pm 7.9$ & .972 \\
\hline $\mathrm{FMI}, \mathrm{kg} / \mathrm{m}^{2}($ mean $\pm \mathrm{SD})$ & & $7.96 \pm 2.54$ & $7.86 \pm 2.74$ & $7.94 \pm 2.58$ & .483 \\
\hline $\mathrm{FFMI}, \mathrm{kg} / \mathrm{m}^{2}($ mean $\pm \mathrm{SD})$ & & $\begin{array}{l}16.39 \pm \\
1.82\end{array}$ & $\begin{array}{l}16.03 \pm \\
1.81\end{array}$ & $\begin{array}{l}16.33 \pm \\
1.82\end{array}$ & $<.001 *$ \\
\hline TFMI, kg/m² (mean \pm SD $)$ & & $4.42 \pm 1.52$ & $4.27 \pm 1.63$ & $4.37 \pm 1.56$ & .06 \\
\hline \multirow[t]{4}{*}{ BMI categories, $\mathrm{n}(\%)$} & $<18$ & $28(1.5)$ & $22(4.8)$ & $20(2.1)$ & \multirow[t]{2}{*}{$<.001 *$} \\
\hline & $\begin{array}{l}18- \\
24.9\end{array}$ & $1096(57.0)$ & $267(57.8)$ & $1363(57.1)$ & \\
\hline & $\begin{array}{l}25- \\
29.9\end{array}$ & $723(37.6)$ & $157(34.0)$ & $880(36.9)$ & \\
\hline & $>30$ & $76(4.0)$ & $16(3.5)$ & $92(3.9)$ & \\
\hline \multirow[t]{3}{*}{ Years of education, $\mathrm{n}(\%)$} & $<6$ & $769(40.0)$ & $242(52.4)$ & $1011(42.4)$ & \multirow[t]{3}{*}{$<.001 *$} \\
\hline & $7-12$ & $746(38.8)$ & $151(32.7)$ & $897(37.6)$ & \\
\hline & $>13$ & $408(21.2)$ & $69(14.9)$ & $477(20.0)$ & \\
\hline Marital status, n (\%) & Married & $1504(78.2)$ & $348(75.3)$ & $1852(77.7)$ & .181 \\
\hline \multirow{3}{*}{$\begin{array}{l}\text { Income, million won per month, } \mathrm{n} \\
(\%)\end{array}$} & $>3$ & $372(19.3)$ & $76(16.5)$ & $448(18.8)$ & \multirow[t]{3}{*}{$<.001 *$} \\
\hline & $1-3$ & $853(44.4)$ & $170(36.8)$ & $1023(42.9)$ & \\
\hline & $<1$ & $698(36.3)$ & $216(46.8)$ & $914(38.3)$ & \\
\hline \multirow[t]{2}{*}{ Residency, n (\%) } & Urban & $1572(81.7)$ & $351(80.1)$ & $1942(81.4)$ & \multirow[t]{2}{*}{.41} \\
\hline & Rural & $351(18.3)$ & $92(19.9)$ & $443(18.6)$ & \\
\hline Current smoker, n (\%) & & 608 (31.6) & 155 (33.5) & $763(32.0)$ & .424 \\
\hline
\end{tabular}




\begin{tabular}{|lllll|}
\hline Alcohol use, $\mathrm{n}(\%)$ & $1133(58.9)$ & $271(58.7)$ & $1404(58.9)$ & .919 \\
\hline Hypertension, $\mathrm{n}(\%)$ & $1075(55.9)$ & $276(59.7)$ & $1351(56.6)$ & .295 \\
\hline Dyslipidemia, $\mathrm{n}(\%)$ & $654(34.0)$ & $134(29.0)$ & $788(33.0)$ & .058 \\
\hline Diabetes mellitus, $\mathrm{n}(\%)$ & $412(21.4)$ & $118(25.5)$ & $530(22.2)$ & .161 \\
\hline Depression, $\mathrm{n}(\%)$ & $52(2.7)$ & $13(2.8)$ & $65(2.7)$ & .936 \\
\hline OA, $\mathrm{n}(\%)$ & $416(21.6)$ & $111(24.0)$ & $527(22.1)$ & .121 \\
\hline Osteoporosis, $\mathrm{n}(\%)$ & $275(14.3)$ & $78(16.9)$ & $353(14.8)$ & .203 \\
\hline WBC, 109/L (mean $\pm \mathrm{SD})$ & $5.7 \pm 1.5$ & $6.1 \pm 1.8$ & $5.8 \pm 1.5$ & $<.001 *$ \\
\hline Hb, mmol/L (mean $\pm \mathrm{SD})$ & $13.5 \pm 1.4$ & $13.1 \pm 1.4$ & $13.4 \pm 1.4$ & $<.001 *$ \\
\hline MMSE-KC (mean \pm SD) & $26.0 \pm 3.0$ & $24.7 \pm 3.54$ & $25.7 \pm 3.1$ & $<.001 *$ \\
\hline
\end{tabular}

Abbreviations: BMI, body mass index; BFP, body fat percentage; $\mathrm{FMI}$, fat mass index; FFMI, fat-free mass index; TFMI, trunk fat mass index; OA, osteoarthritis; WBC, white blood cell; Hb, hemoglobin; MMSE-KC, Mini-Mental State Examination in the Korean version of the CERAD assessment packet

1 million won = approximately 900 USD

$\star P<.05$

Table 2. Body composition characteristics by sex 


\begin{tabular}{|c|c|c|c|}
\hline \multirow[t]{2}{*}{ Characteristic } & Male & Female & \multirow[t]{2}{*}{$P$} \\
\hline & $(n=1131)$ & $(n=1255)$ & \\
\hline Height, cm (mean \pm SD) & $164.8 \pm 5.6$ & $151.8 \pm 5.2$ & $<.001 *$ \\
\hline Weight, kg (mean \pm SD) & $65.2 \pm 9.0$ & $57.2 \pm 8.0$ & $<.001 *$ \\
\hline $\mathrm{BMI}, \mathrm{kg} / \mathrm{m}^{2}($ mean $\pm \mathrm{SD})$ & $23.9 \pm 2.8$ & $24.7 \pm 3.0$ & $<.001 *$ \\
\hline $\mathrm{BFP}, \%($ mean $\pm \mathrm{SD})$ & $26.5 \pm 6.0$ & $37.2 \pm 5.8$ & $<.001 *$ \\
\hline $\mathrm{FMI}, \mathrm{kg} / \mathrm{m}^{2}($ mean $\pm \mathrm{SD})$ & $6.4 \pm 1.9$ & $9.2 \pm 2.3$ & $<.001 *$ \\
\hline $\mathrm{FFMI}, \mathrm{kg} / \mathrm{m}^{2}($ mean $\pm \mathrm{SD})$ & $17.4 \pm 1.6$ & $15.3 \pm 1.3$ & $<.001 *$ \\
\hline $\mathrm{TFMI}, \mathrm{kg} / \mathrm{m}^{2}($ mean $\pm \mathrm{SD})$ & $3.68 \pm 1.3$ & $5.0 \pm 1.4$ & $<.001 *$ \\
\hline Total fat mass, $\mathrm{kg}$ (mean $\pm \mathrm{SD})$ & $17.5 \pm 5.5$ & $21.4 \pm 5.5$ & $<.001 *$ \\
\hline Trunk fat mass, $\mathrm{kg}$ (mean \pm SD) & $10.0 \pm 3.6$ & $11.6 \pm 3.3$ & $<.001 *$ \\
\hline
\end{tabular}

Abbreviations: BMI, body mass index; BFP, body fat percentage; FMI, fat mass index; FFMI, fat-free mass index; TFMI, trunk fat mass index.

$\star P<.05$

Table 3. Univariate and multivariate logistic regression analyses of frailty by BMI categories 


\begin{tabular}{|c|c|c|c|c|}
\hline BMI & Male & & Female & \\
\hline \multirow[t]{2}{*}{ Categories } & OR & $P$ & OR & $P$ \\
\hline & $(95 \% \mathrm{Cl})$ & & $(95 \% \mathrm{Cl})$ & \\
\hline \multicolumn{5}{|l|}{ Unadjusted } \\
\hline Normal weight & reference & & reference & \\
\hline Underweight & $3.00(1.49-6.01)$ & $0.002 *$ & $3.69(1.31-10.36)$ & $0.013^{*}$ \\
\hline Overweight & $0.80(0.57-1.11)$ & 0.185 & $0.97(0.72-1.30)$ & 0.842 \\
\hline Obesity & $0.83(0.31-2.22)$ & 0.716 & $0.89(0.45-1.75)$ & 0.742 \\
\hline \multicolumn{5}{|l|}{ Fully adjusted $^{\dagger}$} \\
\hline Normal weight & reference & & reference & \\
\hline Underweight & $2.92(1.39-6.15)$ & $0.005^{*}$ & $2.80(0.70-8.07)$ & $0.044^{*}$ \\
\hline Overweight & $0.72(0.51-1.03)$ & 0.074 & $1.02(0.74-1.40)$ & 0.887 \\
\hline Obesity & $0.75(0.26-2.14)$ & 0.598 & $0.85(0.42-1.74)$ & 0.667 \\
\hline
\end{tabular}

Abbreviations: $\mathrm{BMI}$, body mass index; $\mathrm{OR}$, odds ratio; $\mathrm{Cl}$, confidence interval.

BMls $\left(\mathrm{kg} / \mathrm{m}^{2}\right)$ were categorized as underweight $\left(<18.5 \mathrm{~kg} / \mathrm{m}^{2}\right)$, normal weight $\left(18.5-24.9 \mathrm{~kg} / \mathrm{m}^{2}\right)$, overweight $\left(25-29.9 \mathrm{~kg} / \mathrm{m}^{2}\right)$, or obese $\left(\geq 30.0 \mathrm{~kg} / \mathrm{m}^{2}\right)$.

*Unless otherwise indicated, the data are reported as relative risk ( $95 \%$ confidence interval).

${ }^{\dagger}$ Adjusted for age, years of education, location of residence, depression, marital status, monthly income, smoking, alcohol drinking, and comorbidities, including diabetes mellitus, dyslipidemia, hypertension, osteoarthritis, and osteoporosis.

$\star P<.05$

Table 4. Univariate and multivariate logistic regression analyses of frailty by body composition 


\begin{tabular}{|c|c|c|c|c|}
\hline & \multicolumn{2}{|l|}{ Male } & \multicolumn{2}{|l|}{ Female } \\
\hline & OR $(95 \% \mathrm{Cl})$ & $\mathbf{P}$ & OR $(95 \% \mathrm{Cl})$ & $\mathbf{P}$ \\
\hline \multicolumn{5}{|l|}{ BMI } \\
\hline Unadjusted & $0.926(0.880-0.975)$ & $.004^{*}$ & $0.969(0.922-1.019)$ & .219 \\
\hline Fully adjusted $^{\dagger}$ & $0.914(0.864-0.967)$ & $.002^{*}$ & $0.973(0.925-1.023)$ & .288 \\
\hline \multicolumn{5}{|l|}{ BFP } \\
\hline Unadjusted & $1.007(0.982-1.032)$ & .600 & $0.996(0.973-1.020)$ & .739 \\
\hline Fully adjusted $^{\dagger}$ & $0.996(0.970-1.022)$ & .757 & $1.012(0.986-1.039)$ & .368 \\
\hline \multicolumn{5}{|l|}{ FMI } \\
\hline Unadjusted & $0.983(0.913-1.060)$ & .662 & $0.969(0.922-1.019)$ & .219 \\
\hline Fully adjusted $^{\dagger}$ & $0.952(0.878-1.033)$ & .236 & $1.011(0.947-1.080)$ & .745 \\
\hline \multicolumn{5}{|l|}{ FFMI } \\
\hline Unadjusted & $0.808(0.737-0.885)$ & $.000 *$ & $0.969(0.922-1.019)$ & .219 \\
\hline Fully adjusted $^{+}$ & $0.812(0.736-0.896)$ & $.000 *$ & $0.891(0.798-0.995)$ & $.041^{\star}$ \\
\hline \multicolumn{5}{|l|}{ TFMI } \\
\hline Unadjusted & $0.923(0.826-1.031)$ & 0.157 & $0.934(0.847-1.030)$ & .173 \\
\hline Fully adjusted $^{\dagger}$ & $881(0.782-0.993)$ & $0.038^{*}$ & $0.951(0.857-1.056)$ & .347 \\
\hline
\end{tabular}

Abbreviations: BMI, body mass index; BFP, body fat percentage; FMI, fat mass index; FFMI, fat-free mass index; TFMI, trunk fat mass index; OR, odds ratio; $\mathrm{Cl}$, confidence interval.

*Unless otherwise indicated, the data are reported as relative risk (95\% confidence interval).

${ }^{\dagger}$ Adjusted for age, years of education, location of residence, depression, marital status, monthly income, smoking, alcohol drinking, and comorbidities, including diabetes mellitus, dyslipidemia, hypertension, osteoarthritis, and osteoporosis

$\star P<.05$

Table 5. Univariate and multivariate logistic regression analyses of poor physical performance (SPPB score $\leq 9)$ and body composition 


\begin{tabular}{|c|c|c|c|c|}
\hline & \multicolumn{2}{|l|}{ Male } & \multicolumn{2}{|l|}{ Female } \\
\hline & OR $(95 \% \mathrm{Cl})$ & $\mathbf{P}$ & OR $(95 \% \mathrm{Cl})$ & $P$ \\
\hline \multicolumn{5}{|l|}{ BMI } \\
\hline Unadjusted & $0.952(0.894-1.014)$ & .129 & $1.046(1.001-1.093)$ & $.045^{*}$ \\
\hline Fully adjusted $^{\dagger}$ & $0.967(0.903-1.036)$ & .337 & $1.058(1.008-1.111)$ & $.022^{*}$ \\
\hline \multicolumn{5}{|l|}{ BFP } \\
\hline Unadjusted & $1.017(0.986-1.049)$ & .293 & $1.001(0.978-1.024)$ & .936 \\
\hline Fully adjusted $^{\dagger}$ & $1.018(0.985-1.052)$ & .277 & $1.034(1.008-1.061)$ & $.010 *$ \\
\hline \multicolumn{5}{|l|}{ FMI } \\
\hline Unadjusted & $1.113(0.925-1.113)$ & .757 & $1.035(0.976-1.097)$ & .245 \\
\hline Fully adjusted $^{\dagger}$ & $1.028(0.929-1.137)$ & .593 & $1.090(1.023-1.161)$ & $.008 *$ \\
\hline \multicolumn{5}{|l|}{ FFMI } \\
\hline Unadjusted & $0.836(0.748-0.935)$ & $.002 *$ & $1.096(0.996-1.207)$ & .062 \\
\hline Fully adjusted $^{\dagger}$ & $0.865(0.767-0.974)$ & $.017^{*}$ & $1.002(0.899-1.115)$ & .977 \\
\hline \multicolumn{5}{|l|}{ TFMI } \\
\hline Unadjusted & $1.030(0.898-1.180)$ & 0.674 & $1.080(0.984-1.186)$ & .106 \\
\hline Fully adjusted $^{\dagger}$ & $1.043(0.901-1.208)$ & 0.573 & $1.121(1.014-1.240)$ & $.026 *$ \\
\hline
\end{tabular}

Abbreviations: SPPB, short physical performance battery; BMI, body mass index; BFP, body fat percentage; FMI, fat mass index; FFMI, fat-free mass index; TFMI, trunk fat mass index; OR, odds ratio; $\mathrm{Cl}$, confidence interval.

Unless otherwise indicated, data are reported as relative risk (95\% confidence interval).

${ }^{\dagger}$ Adjusted for age, years of education, location of residence, depression, marital status, monthly income, smoking, alcohol drinking, and comorbidities, including diabetes mellitus, dyslipidemia, hypertension, osteoarthritis, and osteoporosis

$\star P<.05$ 